\title{
Total Exchange Flow, Entrainment, and Diffusive Salt Flux in Estuaries
}

\author{
TAO WANG \\ College of Oceanography, Hohai University, Nanjing, China, and Woods Hole Oceanographic Institution, Woods \\ Hole, Massachusetts \\ W. ROCKWELL GEYER \\ Woods Hole Oceanographic Institution, Woods Hole, Massachusetts \\ PARKER MACCREADY \\ School of Oceanography, University of Washington, Seattle, Washington
}

(Manuscript received 22 November 2016, in final form 20 January 2017)

\begin{abstract}
The linkage among total exchange flow, entrainment, and diffusive salt flux in estuaries is derived analytically using salinity coordinates, revealing the simple but important relationship between total exchange flow and mixing. Mixing is defined and quantified in this paper as the dissipation of salinity variance. The method uses the conservation of volume and salt to quantify and distinguish the diahaline transport of volume (i.e., entrainment) and diahaline diffusive salt flux. A numerical model of the Hudson estuary is used as an example of the application of the method in a realistic estuary with a persistent but temporally variable exchange flow. A notable finding of this analysis is that the total exchange flow and diahaline salt flux are out of phase with respect to the spring-neap cycle. Total exchange flow reaches its maximum near minimum neap tide, but diahaline salt transport reaches its maximum during the maximum spring tide. This phase shift explains the strong temporal variation of stratification and estuarine salt content through the springneap cycle. In addition to quantifying temporal variation, the method reveals the spatial variation of total exchange flow, entrainment, and diffusive salt flux through the estuary. For instance, the analysis of the Hudson estuary indicates that diffusive salt flux is intensified in the wider cross sections. The method also provides a simple means of quantifying numerical mixing in ocean models because it provides an estimate of the total dissipation of salinity variance, which is the sum of mixing due to the turbulence closure and numerical mixing.
\end{abstract}

\section{Introduction}

An estuary can be thought of as a mixing machine that combines high-salinity water from the ocean with freshwater from the river to form intermediate-salinity water. The key elements for this process are the river; the exchange flow, which supplies ocean water and exports mixed water; and mixing, which blends them. The exchange flow and mixing determine the physical conditions in estuaries as well as the transport of pollutants, suspended sediment, and nutrients. Therefore, studying the linkage between exchange flow and mixing is fundamental to understanding the physical dynamics and biogeochemical processes in estuaries. In this paper, the

Corresponding author: Tao Wang, haidawangtao@163.com exchange flow refers to the tidally averaged alongchannel flow, which satisfies the Knudsen relationships (Knudsen 1900). The word mixing is defined explicitly as the rate of loss of salinity variance due to turbulent and molecular diffusion. These diffusive processes also drive diffusive salt flux and entrainment across isohalines, which we distinguish with analysis developed in the paper. The explanations of the terms related to exchange flow and mixing in this paper are shown in Table 1.

The traditional method to quantify the exchange flow uses Eulerian averages (Pritchard 1956; Lerczak et al. 2006; MacCready and Geyer 2010). However, a problem arises for Eulerian averages in the along-channel subtidal salt balance, in which a term related to the tidaltime scale correlation of salinity with tidal currents appears. This term is sometimes parameterized as a tidal 
TABLE 1. Definitions of terminologies related to exchange flow and mixing in this paper.

\begin{tabular}{|c|c|}
\hline Terminology & Definition \\
\hline Exchange flow & $\begin{array}{l}\text { Tidally averaged circulation that crosses isohaline surfaces, entering the estuary at higher salinity and } \\
\text { leaving at lower salinity, satisfying Knudsen relations. (Crossing isohaline surfaces is necessary. } \\
\text { Water that comes in and out at the same salinity, for instance, in a well-mixed bay, is not defined as } \\
\text { exchange flow.) }\end{array}$ \\
\hline Eulerian exchange flow & Exchange flow obtained by Eulerian averaging. \\
\hline Total exchange flow & Exchange flow obtained by isohaline averaging. \\
\hline Mixing & The rate of loss of salinity variance. \\
\hline Physical mixing & Mixing induced by turbulent and molecular diffusion. \\
\hline Numerical mixing & Mixing induced by truncation errors in the numerical advection scheme. \\
\hline Diffusive salt flux & $\begin{array}{l}\text { Salt flux induced by turbulent and molecular diffusion (in numerical models, also including down- } \\
\text { gradient salt transport due to numerical truncation errors). }\end{array}$ \\
\hline Turbulent salt flux & Salt flux induced by turbulent process. \\
\hline Entrainment velocity & $\begin{array}{l}\text { The velocity normal to a surface of constant salinity, that is, the difference between the fluid velocity } \\
\text { and the velocity of the isohaline surface. }\end{array}$ \\
\hline
\end{tabular}

dispersion term using an ad hoc along-channel diffusivity [e.g., Hansen and Rattray 1965; see review by Geyer and MacCready (2014)]. However, the mechanisms contributing to tidal dispersion vary for different estuaries (Okubo 1973; Fischer 1976; Hunkins 1981; Lewis and Lewis 1983; MacCready and Geyer 2010) and even for different cross sections in one estuary (Chen et al. 2012; Wang et al. 2015). Some studies have shown that when using the Eulerian method, time-varying processes were represented as dispersion when they were more appropriately represented as part of the advective exchange flow (Dronkers and van de Kreeke 1986; Geyer and Nepf 1996). A similar problem also occurred in atmosphere and largescale ocean studies. When zonal averaging was performed at constant height, Ferrel cells appeared in the atmosphere (Townsend and Johnson 1985), and the Deacon cell appeared in the Southern Ocean (Doos and Webb 1994). These spurious cells can be avoided when averaging along isopycnals (Townsend and Johnson 1985; McIntosh and McDougall 1996). The results of isopycnal-mean methods are usually represented in the density coordinate, with the density instead of depth as the vertical axis (Lumpkin and Speer 2007; Mazloff et al. 2013).

In most estuaries, the salinity is the main factor that influences density, so MacCready (2011) proposed an alternative averaging method (the isohaline averaging method) to quantify the exchange flow in estuaries and referred to the obtained exchange flow as the total exchange flow (TEF) because it represents the flux of water into and out of the estuary due to all processes (including tidal dispersion processes) that occur in distinct salinity classes, so it gets rid of the tidal dispersion term in the subtidal salt balance. Chen et al. (2012) and Wang et al. (2015) showed that the Eulerian exchange flow exhibited a large, longitudinal variation in the Hudson estuary due to the variation of the tidal dispersion term, whereas TEF provided a smooth, continuous variation. These analyses demonstrated that TEF provides a more robust means of quantifying exchange flow in regions of complex interactions between tidal flow and topography. Another advantage of TEF is that it explicitly satisfies the Knudsen relationship relating exchange flow, stratification, and freshwater inflow (Knudsen 1900; MacCready and Geyer 2010), so it is well suited to addressing the salt balance of estuaries.

TEF, as developed to date, addresses the isohaline transport, but it has not been used to quantify the magnitude or distribution of fluxes across isohaline surfaces. Yet the TEF framework is well suited to addressing diahaline (or diapycnal) fluxes because, as will be shown in the next section, the diahaline flux is readily estimated by the divergence of TEF along an isohaline control volume.

In this paper, entrainment velocity (or diahaline velocity) is defined as the velocity normal to a surface of constant salinity, that is, the difference between the fluid velocity and the velocity of the isohaline surface, which typically is not fixed in space. Under steady conditions, the divergence of volume transport between two isohalines balances entrainment across them. However, in realistic estuaries, because of the temporal variation of tides, river flow, wind, and other nonperiodic forcing, the salt balance is inherently unsteady (Jay and Smith 1990; Bowen and Geyer 2003; Ralston et al. 2008; Lerczak et al. 2009). Under unsteady conditions, entrainment is no longer equal to the longitudinal gradient of isohaline transport. Temporal variation of the volume between isohalines needs to be considered to balance volume and to quantify entrainment (MacCready and Geyer 2001; MacCready et al. 2002; MacDonald and 
Geyer 2004; MacDonald and Horner-Devine 2008). One main contribution of this paper is adding entrainment to the TEF framework to complete the circuit of estuarine circulation by consideration of the timedependent term.

Entrainment provides advective transport of salt across isohaline surfaces, while turbulent and molecular salt transport provide diffusive salt transport. Entrainment is often thought of as mixing because entrainment only occurs in the presence of diffusive flux (turbulent and molecular); however, the salt transport by entrainment and diffusive flux are distinct and separable, as discussed by McDougall and You (1990) and McDougall and Dewar (1998). This can be shown by considering the onedimensional (vertical) conservation equation for salinity:

$$
\frac{\partial s}{\partial t}+w \frac{\partial s}{\partial z}=-\frac{\partial}{\partial z} \overline{s^{\prime} w^{\prime}}
$$

where $s$ and $w$ are Reynolds-averaged salinity and vertical velocity, primed quantities are turbulent fluctuations, the overbar represents averaging over turbulent time scales, and molecular diffusion is neglected. If Eq. (1.1) is viewed in a frame of reference moving vertically with an isohaline, the reference frame moves vertically with the Reynolds-averaged salinity. This eliminates the first term, and instead of $w$ we have $w_{e}$, which is the velocity relative to the isohaline or the entrainment velocity. The vertical diffusion is the same because the change in reference frame does not alter the correlations of the fluctuations. The vertical coordinate is replaced by the salinity coordinate using

$$
\frac{\partial}{\partial z}=\frac{\partial s}{\partial z} \frac{\partial}{\partial s}
$$

And as long as $\partial s / \partial z$ does not vanish, the transformed equation becomes simply

$$
w_{e}=-\frac{\partial}{\partial s} \overline{s^{\prime} w^{\prime}},
$$

as demonstrated by McDougall and You (1990), and it also can be applied in a three-dimensional context, as derived in section $2 b$, noting that turbulent flux divergence is generally maximal in the vertical direction. Entrainment can go either direction with respect to the salinity gradient, but it always goes in the direction of greater mixing. In estuaries both the salt flux due to the entrainment (times the local salinity) and the turbulent salt flux may contribute significantly to net salt flux across an isohaline. The TEF framework provides an effective means of distinguishing entrainment and diffusive salt flux and calculating the net salt flux across an isohaline, because Eq. (1.3) demonstrates that the two quantities have a simple relationship in isohaline coordinates. Equation (1.3) is suitable for the realistic ocean and estuaries when the molecular diffusion is negligible, that is, when diffusive salt flux is equal to turbulent salt flux.

Averaged over a long enough time scale to minimize the time variability of the salinity distribution, the divergence of isohaline and diahaline salt transports (due to both entrainment and turbulence) is in balance. However, the actual exchange flow exhibits marked temporal and spatial variability (Sutherland et al. 2011), so the isohaline and diahaline transport may occur at different places and times in the estuary. To link isohaline transport with diahaline transport in time-dependent estuarine regimes, the time variability of the salt content has to be explicitly quantified. This can be accomplished within the TEF framework by introducing the temporal variation of the volume of fluid within a given salinity class. With the combination of the temporal variation term and the TEF transport variables, salt conservation can be used to quantify the diahaline entrainment and diffusive fluxes irrespective of the temporal or spatial variability of the domain.

In section 2, we add entrainment to the TEF framework and reveal the linkage among TEF, entrainment, and diffusive salt flux theoretically, emphasizing the temporal variation of the volume within a given salinity class. In section 3, a validated numerical model of the Hudson estuary is used as an example to show TEF, entrainment, and diffusive salt flux in the Hudson estuary, including the temporal variability associated with the spring-neap cycle and spatial variability due to realistic topography. In section 4 , we demonstrate that the method also provides a simple means of quantifying numerical mixing in ocean models.

\section{Theoretical relationship among TEF, entrainment, and diffusive salt flux}

Here, the TEF analysis is considered within an estuarine control volume, with explicit consideration of timedependent variation of salinity. Based on this framework, we relate the divergence of along-isohaline flux to the diahaline flux, and by considering both volume and salt conservation we obtain the simple relationship between entrainment and diahaline diffusive salt flux.

\section{a. Relationship between total exchange flow and entrainment}

The instantaneous volume flux $Q(x, s)$ through a cross section at position $x$ with salinity greater than $s$ is defined as 


$$
Q(x, s) \equiv \int_{A(x, s)} u d A,
$$

where $A(x, s)$ is the instantaneous area with salinity greater than $s$ at cross-section $x$, and $u$ is the alongchannel velocity. The volume flux in a specific salinity class $-\partial Q / \partial s$ can be obtained through differentiating $Q$ with respect to salinity:

$-\frac{\partial Q(x, s)}{\partial s}=\lim _{\delta s \rightarrow 0} \frac{Q(x, s-\delta s / 2)-Q(x, s+\delta s / 2)}{\delta s}$.

According to the definition of TEF (MacCready 2011), the inflow and outflow volume flux of TEF can be defined as

$Q_{\text {in }}=\left.\int\left\langle-\frac{\partial Q}{\partial s}\right\rangle\right|_{\text {in }} d s, \quad Q_{\text {out }}=\left.\int\left\langle-\frac{\partial Q}{\partial s}\right\rangle\right|_{\text {out }} d s$,

where \langle\rangle indicates the temporal average (typically a tidal time scale), and "in" means we only count $\langle-\partial Q / \partial s\rangle$ in the integral when it brings water into the estuary. Note that here we apply the temporal average to Eq. (2.3), whereas in MacCready (2011) it was applied when defining $Q$. This small formal change makes no difference to $Q_{\text {in }}$ and $Q_{\text {out }}$ but allows a more flexible theoretical use of $Q$. Although $Q_{\text {in }}$ and $Q_{\text {out }}$ are usually used to represent the magnitude of TEF, the isohaline transport, that is, $\langle-\partial Q / \partial s\rangle$, provides the basis for the entire isohaline and diahaline salt transport in the estuary, based on the following control-volume analysis.

To implement the control-volume analysis, we divide the estuary into segments along the estuarine channel. Each segment is bounded with two adjacent cross sections and one specific isohaline surface, as shown in Fig. 1. Each segment has a time-varying volume $V\left(x_{i}, s\right)$. Based on volume conservation, the entrainment flux across the upper-bounding isohaline surface can be obtained by

$Q_{e}\left(x_{i}, s\right)=Q\left(x_{i}, s\right)-Q\left(x_{i+1}, s\right)-\frac{\partial V\left(x_{i}, s\right)}{\partial t}$

if we introduce the volume in a specific salinity class $-\partial V\left(x_{i}, s\right) / \partial s$, obtained through differentiating $V$ with respect to salinity. The minus sign means that the differential volume is positive when we take the derivative with respect to salinity in the standard way [i.e., in the sense shown in Eq. (2.5)]:

$$
-\frac{\partial V\left(x_{i}, s\right)}{\partial s}=\lim _{\delta s \rightarrow 0} \frac{V\left(x_{i}, s-\delta s / 2\right)-V\left(x_{i}, s+\delta s / 2\right)}{\delta s} .
$$

Equation (2.4) can be written as
$Q_{e}\left(x_{i}, s\right)=\int_{s}^{s_{0}}-\frac{\partial}{\partial s}\left[Q\left(x_{i}, s\right)-Q\left(x_{i+1}, s\right)-\frac{\partial V\left(x_{i}, s\right)}{\partial t}\right] d s$,

where $s_{0}$ indicates the ocean salinity because it makes no contribution to the integral for salinities higher than the maximum salinity in the control volume $V\left(x_{i}, s\right)$. Therefore, the diahaline volume transport (entrainment) $Q_{e}\left(x_{i}, s\right)$ and isohaline transport $-\partial Q / \partial s$ are linked to each other as long as we include the time-dependent term. If a long enough temporal average is considered to satisfy $\left\langle\partial V\left(x_{i}, s\right) / \partial t\right\rangle=0$, the along-isohaline divergence of isohaline transport balances entrainment. However, the estuarine salt balance varies at multiple time scales, not just tidal but also the spring-neap modulation period as well as time scales related to river and wind forcing. To adequately address the broad range of temporal variability of the estuarine salt balance, the time-dependent term must be retained.

\section{b. Relationship between entrainment and diffusive salt flux}

Just as the diahaline volume flux can be quantified by volume conservation in salinity space, the diahaline salt flux can be similarly quantified. The salt flux is represented here as $F(x, s)$ for isohaline salt flux and as $F_{s}$ for diahaline salt flux (Fig. 1). Once an expression for the total diahaline salt flux has been derived, the contribution of diffusive salt flux is determined by subtracting the salt flux due to entrainment.

The salt conservation in the control volume satisfies

$$
F_{s}\left(x_{i}, s\right)=F\left(x_{i}, s\right)-F\left(x_{i+1}, s\right)-\frac{\partial V_{s}\left(x_{i}, s\right)}{\partial t},
$$

where the last term accounts for the time variations of the salt content bounded by that isohaline within a segment. The isohaline salt flux is calculated as

$$
F\left(x_{i}, s\right)=\int_{s}^{s_{0}}-\frac{\partial Q\left(x_{i}, s\right)}{\partial s} s d s,
$$

and the salt content is given by

$$
V_{s}\left(x_{i}, s\right)=\int_{s}^{s_{0}}-\frac{\partial V\left(x_{i}, s\right)}{\partial s} s d s .
$$

The expression for the diahaline salt flux [Eq. (2.7)] can then be written as

$$
\begin{aligned}
F_{s}\left(x_{i}, s\right) & =\int_{s}^{s_{0}}-s \frac{\partial}{\partial s}\left[Q\left(x_{i}, s\right)-Q\left(x_{i+1}, s\right)-\frac{\partial V\left(x_{i}, s\right)}{\partial t}\right] d s \\
& =\int_{s}^{s_{0}}-s \frac{\partial Q_{e}\left(x_{i}, s\right)}{\partial s} d s .
\end{aligned}
$$



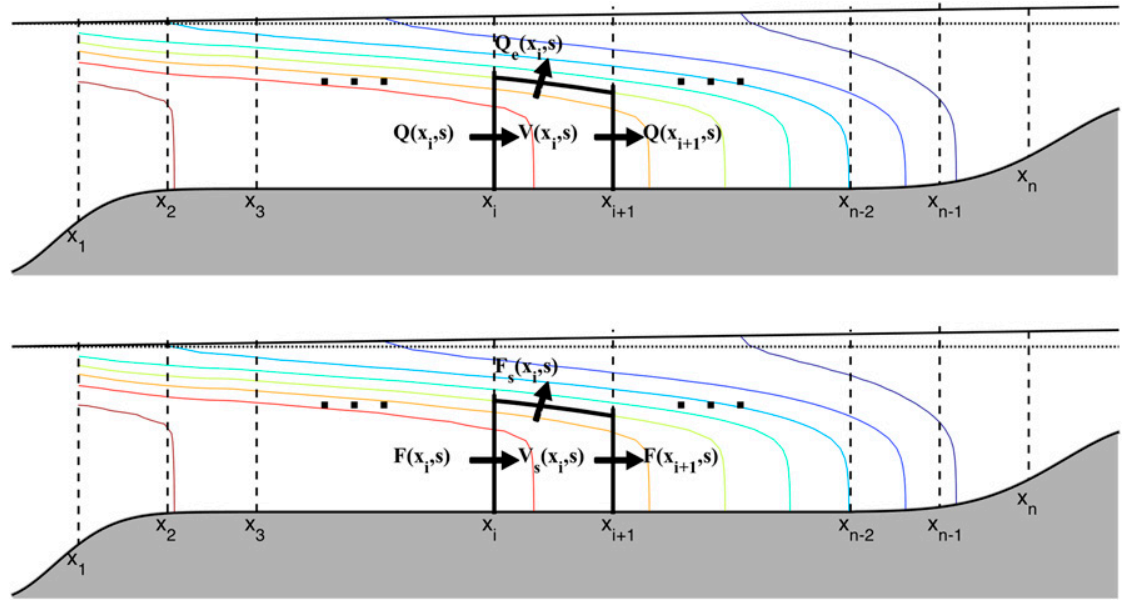

FIG. 1. Schematic diagram of the control-volume method. The estuary is divided into $n$ segments by cross sections. The symbols $V\left(x_{i}, s\right)$ and $V_{s}\left(x_{i}, s\right)$ indicate the instantaneous control volume and the salt content in the control volume bounded by sections $x_{i}, x_{i+1}$, and the specific isohaline surface with salinity $s$. The symbols $Q\left(x_{i}, s\right)$ and $F\left(x_{i}, s\right)$ indicate the volume flux and salt flux with salinity greater than $s$ at section $x_{i}, Q\left(x_{i+1}, s\right)$ and $F\left(x_{i+1}, s\right)$ are the volume flux and salt flux with salinity greater than $s$ at section $x_{i+1}$, and $Q_{e}\left(x_{i}, s\right)$ and $F_{s}\left(x_{i}, s\right)$ indicate the volume flux and salt flux across the isohaline surface $s$ between the two sections $x_{i}$ and $x_{i+1}$.

Now we note that the diahaline salt flux $F_{s}$ is due to the contributions of both entrainment and diffusion, and the entrainment salt flux is simply equal to $s Q_{e}$, so the diahaline diffusive salt flux $F_{m}$ is obtained by their difference:

$$
F_{m}\left(x_{i}, s\right)=F_{s}\left(x_{i}, s\right)-s Q_{e}\left(x_{i}, s\right) .
$$

Combining Eqs. (2.10) and (2.11), we obtain a simple expression for the diahaline diffusive salt flux:

$$
\begin{aligned}
F_{m}\left(x_{i}, s\right) & =-\int_{s}^{s_{0}} s \frac{\partial Q_{e}\left(x_{i}, s\right)}{\partial s} d s-s Q_{e}\left(x_{i}, s\right) \\
& =-\int_{s}^{s_{0}} \frac{\partial\left[s Q_{e}\left(x_{i}, s\right)\right]}{\partial s} d s+\int_{s}^{s_{0}} Q_{e}\left(x_{i}, s\right) d s-s Q_{e}\left(x_{i}, s\right) \\
& =\int_{s}^{s_{0}} Q_{e}\left(x_{i}, s\right) d s
\end{aligned}
$$

Equation (2.12) shows the simple integral relationship between diffusive salt flux $F_{m}$ and entrainment volume flux $Q_{e}$. Note that if we take the derivative of Eq. (2.12) with respect to $s$, we obtain

$$
Q_{e}=-\partial F_{m} / \partial s,
$$

which is a volumetric equivalent to the McDougall and You (1990) expression [Eq. (1.3)] for the relationship between entrainment and mixing. In realistic ocean and estuaries, $F_{m}$ refers to the diffusive salt flux due to molecular and turbulent mixing, but in numerical models, $F_{m}$ refers to the diffusive salt flux due to molecular, turbulent, and numerical mixing.

With Eq. (2.12), we can use the distributions of salinity and entrainment to quantify diffusive salt flux and also can use the diahaline gradient of diffusive salt flux to quantify entrainment. In previous studies (e.g., MacCready and Geyer 2001; MacCready et al. 2002; MacDonald and Geyer 2004; MacDonald and HornerDevine 2008), they realized diffusive salt flux could be quantified with known entrainment volume and salt flux, but they did not give the simple relationship [Eq. (2.12)] between them and address the basic principle in which entrainment is related to the diahaline gradient of diffusive salt flux. This analysis yields that simple but important relationship.

Therefore, with emphasizing the importance of the time-dependent term, we show the relationship among isohaline and diahaline volume transports and diffusive salt flux [Eqs. (2.6) and (2.12)]. Entrainment (i.e., diahaline volume flux) and diahaline diffusive salt flux can be quantified with distributions of salinities and longitudinal velocities. In the next section, the output of a numerical model of the Hudson estuary is used as an example to show how this developed method works and what it can reveal in a realistic estuary. The Hudson is a relatively simple example for the application of this method because of the dominant role of estuarine circulation in its salt balance; however, the method is 
(a)Model domain

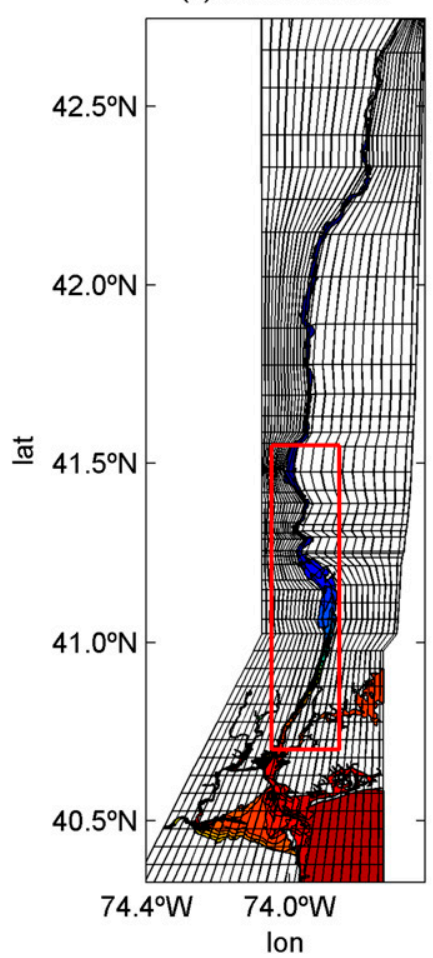

(b)Estuarine region

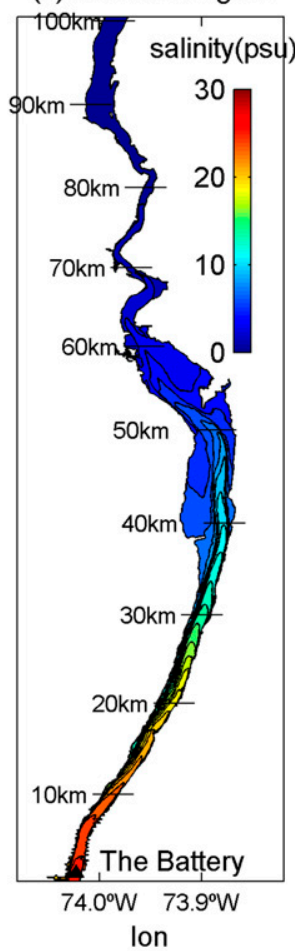

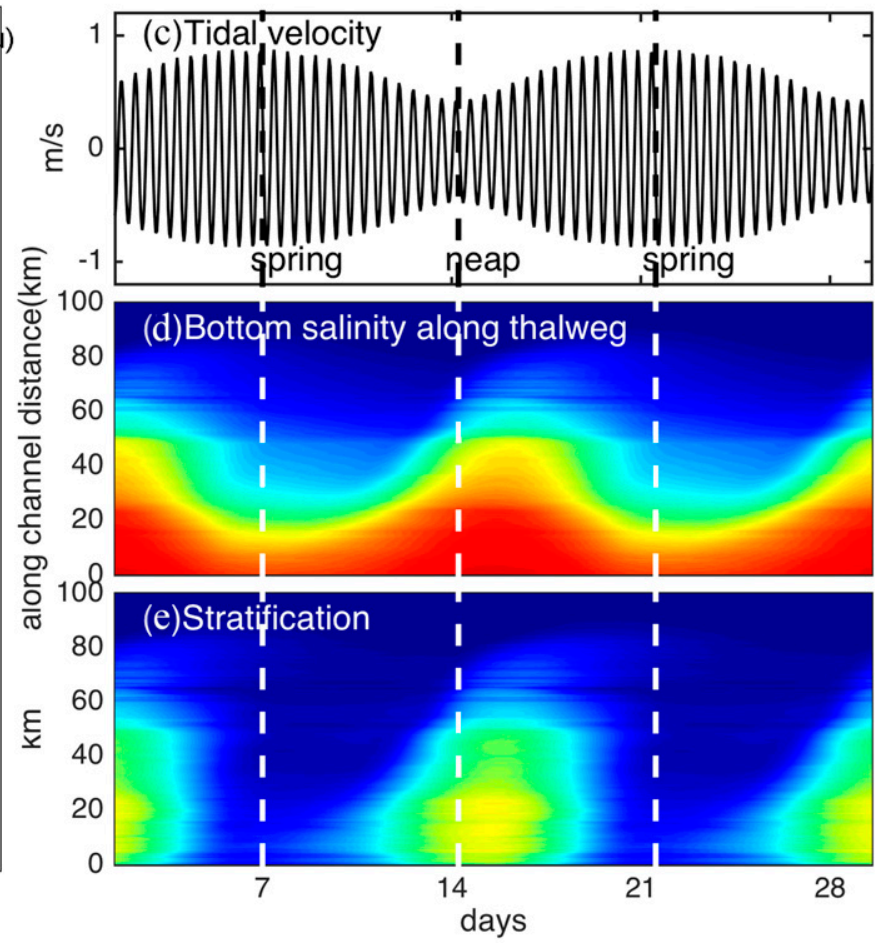

FIG. 2. (a) Entire model domain and horizontal grid region. The region in the red box indicates the estuarine region studied in this paper. (b) Spring-neap-averaged bottom salinity in the estuarine region studied in this paper. (c) Cross-sectionally averaged velocity at the battery, indicating the spring-neap and tidal variations of velocity. (d) Tidally averaged salinity along the thalweg, showing the springneap variation of salt intrusion. (e) The difference between tidally averaged bottom and surface salinity along thalweg, indicating the spring-neap variation of stratification.

equally applicable to any estuary with a persistent alongestuary salinity gradient.

\section{TEF, entrainment, and diffusive salt flux in the Hudson estuary}

In this section, the theory developed above is used to study TEF, entrainment, and diffusive salt flux in the Hudson estuary with numerical model results. Their time-averaged relationship as well as temporal and spatial variability is discussed.

\section{a. Numerical model}

The model application is an extension of the ROMS model of the Hudson estuary by Warner et al. (2005), extended to include the New York Harbor and the influence of the East River on the salinity in the Hudson estuary (Warner et al. 2010). The grid for this application is 530 cells across estuary by 1133 cells along estuary (Fig. 2) in lateral resolution of about $50 \mathrm{~m}$ and alongestuary resolution of about $200 \mathrm{~m}$ in the lower estuary. In the vertical, the grid has 16 sigma layers. Whereas previous applications of the model were used to reproduce specific observation periods, these idealized simulations use steady discharge and simplified tides in order to isolate the response of the estuary to springneap variations in forcing. The southern boundary is forced by $\mathrm{M}_{2}$ and $\mathrm{S}_{2}$ tidal constituents, and river discharge is set to $500 \mathrm{~m}^{3} \mathrm{~s}^{-1}$, representative of moderate discharge conditions. Following a model spinup period of 10 days, the model exhibits periodic variations over the spring-neap time scale. When averaging over a spring-neap cycle, a steady-state balance can be assessed. More relevant to realistic estuaries, however, is the time-dependent behavior of the salt balance resulting from spring-neap variability of exchange flow and diahaline salt flux, which will also be discussed in this section.

\section{b. Quantification of entrainment and diffusive salt flux using TEF}

To see how the TEF equations for entrainment [Eq. (2.6)] and diffusive salt flux [Eq. (2.12)] are applied between any two cross sections in the realistic estuary, we take a large control volume extending between 0 and $20 \mathrm{~km}$ along the Hudson estuary as an example. The 
$(\mathbf{a})<-\partial \mathbf{Q}(\mathbf{0}, \mathbf{s}) / \partial \mathbf{s}>$

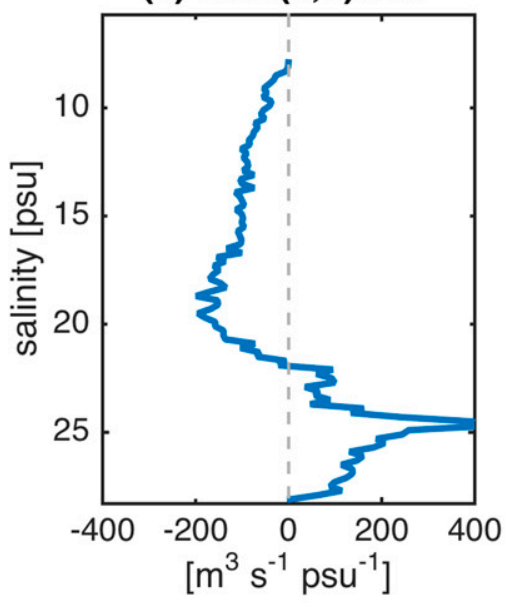

(b) $<-\partial \mathbf{Q}(20, \mathbf{s}) / \partial \mathbf{s}>$

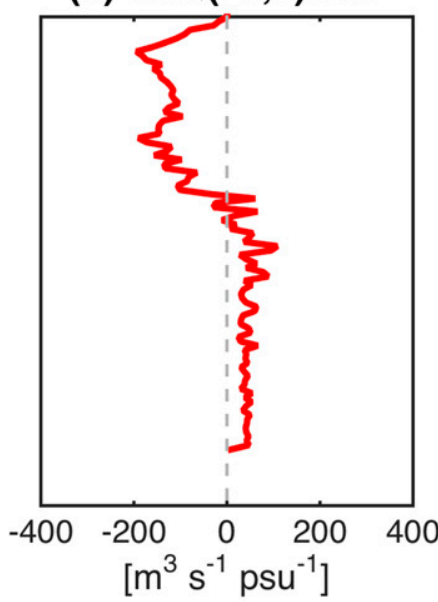

$(\mathrm{e})<Q_{\mathrm{e}}>$
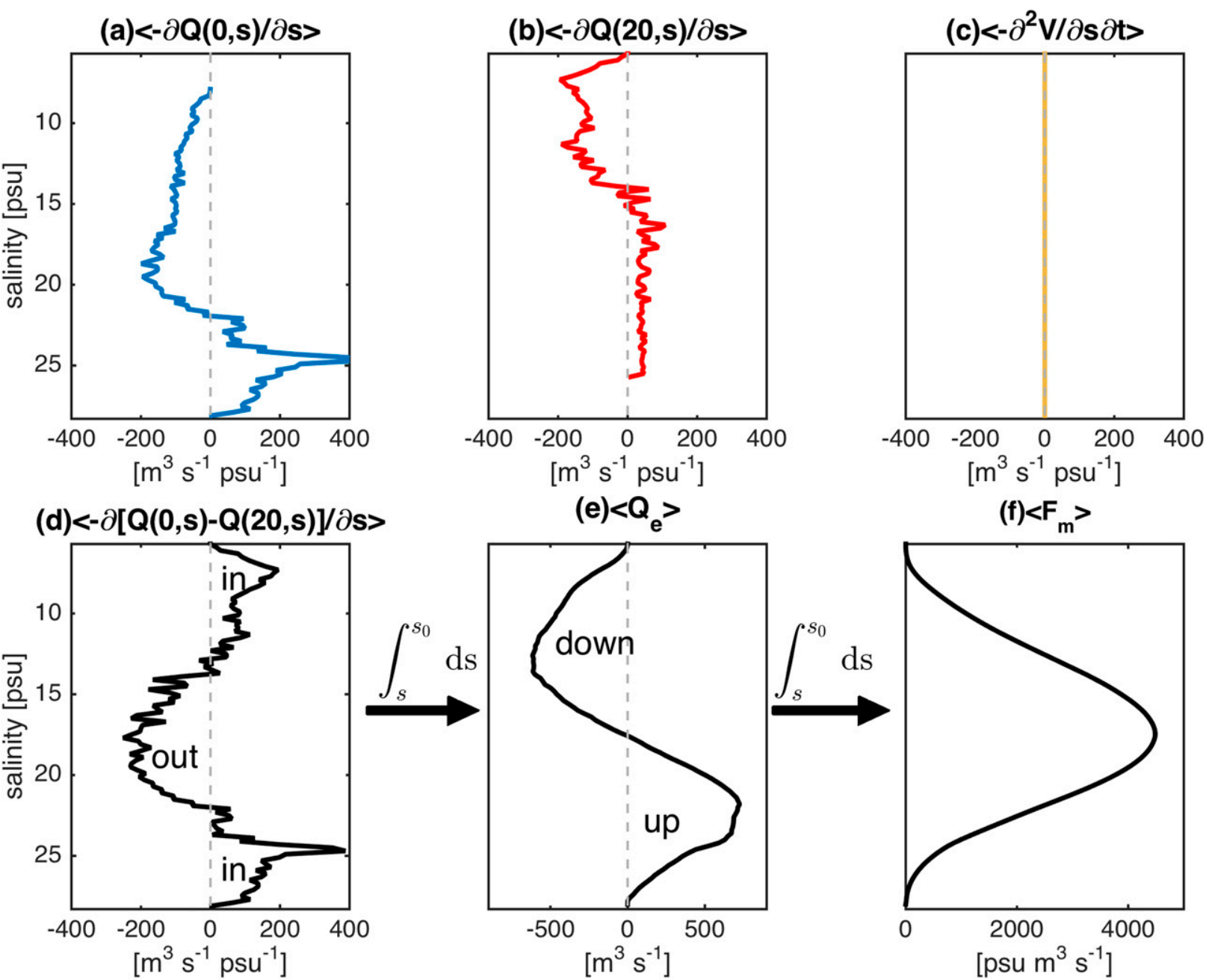

FIG. 3. Spring-neap-averaged isohaline transports at (a) 0 and (b) $20 \mathrm{~km}$. Positive values mean landward. (c) Time-dependent term in Eq. (2.6). (d) Net convergence of isohaline transports between 0 and $20 \mathrm{~km}$. Positive values indicate into the volume. (e) Entrainment volume flux across every isohaline between 0 and $20 \mathrm{~km}$. Positive values mean from high salinity to low salinity. (f) Diffusive salt flux across every isohaline between 0 and $20 \mathrm{~km}$. The integrals among (d), (e), and (f) indicate the values in (d), (e), and (f) satisfy integral relationships.

TEF method can also be applied to the control volume extending from the mouth to the end of the salt intrusion, but it is a particular case that merely has one boundary (estuarine mouth) where salt flux occurs, so we take a common example $(0-20 \mathrm{~km})$ in this paper. The calculations were performed with salinity bins at 0.2 -psu intervals. We start with a steady-state case based on an average over a spring-neap cycle. In this case the volumetric time rate of change term in Eq. (2.6) vanishes, that is, $\left\langle\partial V\left(x_{i}, s\right) / \partial t\right\rangle=0$, because the salinity structure does not change after a spring-neap cycle. The results of spring-neap-averaged isohaline transports $\langle-\partial Q(0, s) / \partial s\rangle$, $\langle-\partial Q(20, s) / \partial s\rangle$, entrainment volume flux $Q_{e}$, and diffusive salt flux $F_{m}$ between 0 and $20 \mathrm{~km}$ are shown in Fig. 3 .

The isohaline transports show that the exchange flow drives high-salinity water landward and low-salinity water oceanward (Figs. 3a,b). The divergence of isohaline transport (Fig. 3d) indicates that both high-salinity and low-salinity water enter the control volume, and intermediate-salinity water leaves the control volume. This illustrates a fundamental characteristic of exchange flow and mixing that, in the absence of internal sources, the flow leaving a control volume has to have characteristics intermediate between the characteristics of the water entering. The entrainment volume flux (Fig. 3e), which is simply the integral in salinity space of the isohaline transport, represents the diahaline flux that transports low-salinity and high-salinity water to the intermediate-salinity classes. The diahaline diffusive salt flux (Fig. 3f) is calculated by integrating the entrainment in salinity space, as Eq. (2.12) indicates. The maximum diffusive salt flux occurs at the isohaline with 


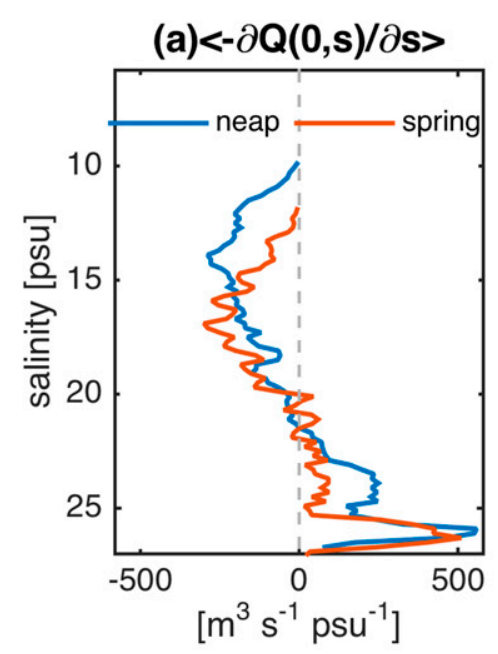

(d) $<-\partial[\mathbf{Q}(\mathbf{0 , s})-\mathbf{Q}(\mathbf{2 0}, \mathbf{s})-\partial \mathrm{V} / \partial \mathrm{t}] / \partial \mathbf{s}>$

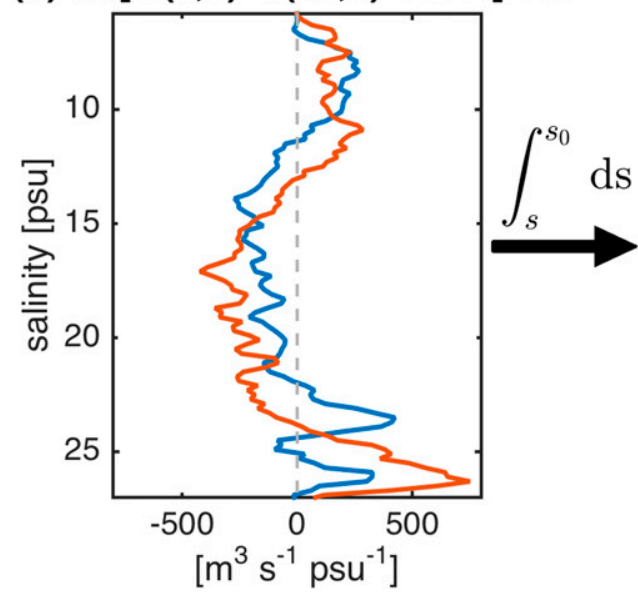

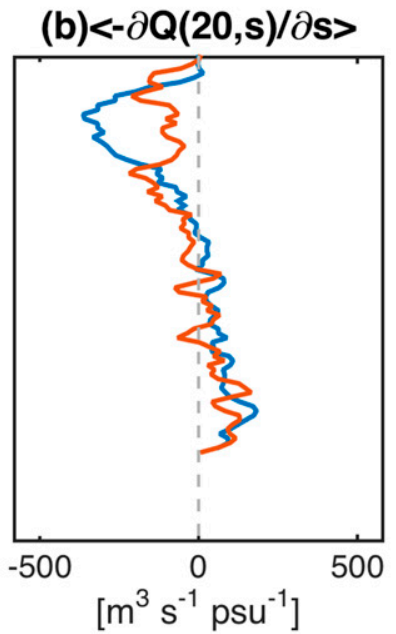

(e) $<Q_{e^{-}}$

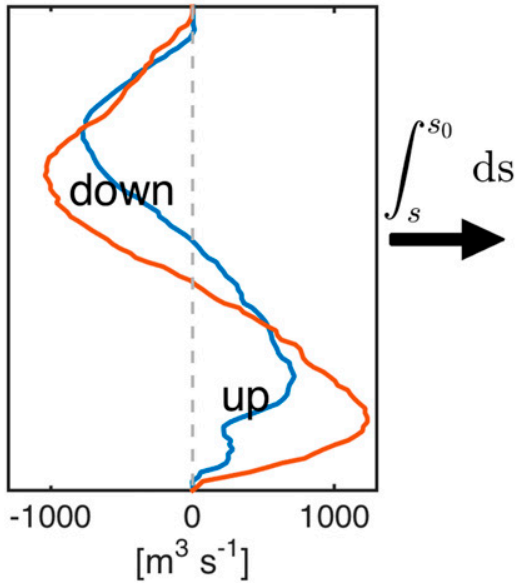

(c) $<-\partial^{2} \mathrm{~V} / \partial \mathbf{s} \partial \mathrm{t}>$

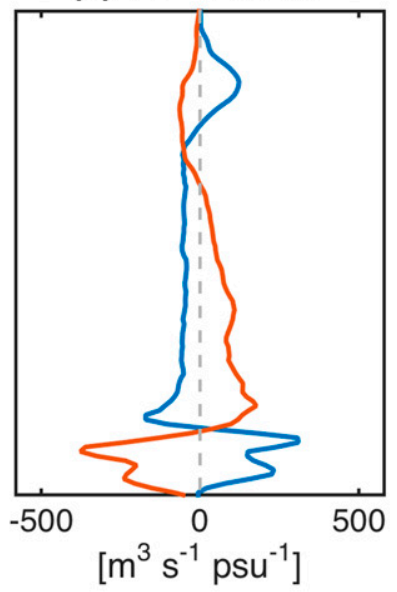

$(\mathrm{f})<\mathrm{F}_{\mathrm{m}}>$

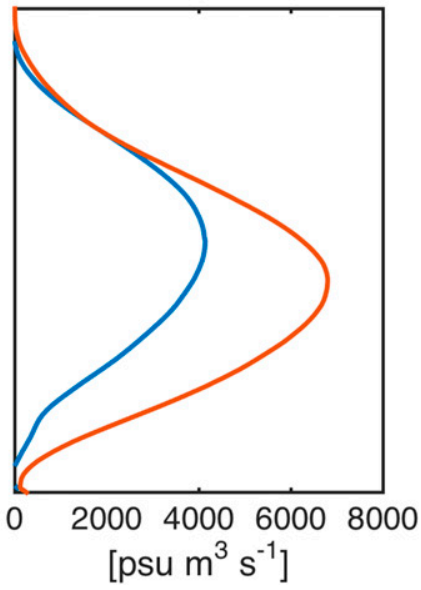

FIG. 4. As in Fig. 3, but for the tidal average (35-h low-pass filter) of the terms in Eqs. (2.6) and (2.12) during 2 days before the minimum neap (blue) and minimum spring (orange) tides, respectively.

0 entrainment flux. This relationship between the vertical structure of diffusive salt flux and entrainment is consistent with Eq. (1.3) (McDougall and You 1990) that the entrainment is directed toward the region of maximal diffusive salt flux. It also makes intuitive sense in that mixing transforms the water of low and high salinity to intermediate salinity, which requires a volumetric flux across isohalines toward the intermediatesalinity values.

To show the role of the time-dependent term in Eq. (2.6), which is important especially during the transitions between spring and neap tides, two examples under unsteady-state conditions [tidal average for Eq. (2.6) and Eq. (2.12)], one during 2 days before minimum neap and the other during 2 days before maximum spring, are shown in Fig. 4. The calculation region again is between 0 and $20 \mathrm{~km}$. During neaps, $\langle-\partial Q / \partial s\rangle$ is high, indicative of strong exchange flow, but $\left\langle-\partial^{2} V / \partial s \partial t\right\rangle$ is positive at low and high salinities, indicating that the import at low and high salinity is accumulating within their respective salinity bins rather than being entrained across isohalines. This corresponds to an increase in stratification during neap tides. The reverse happens during spring tides, in which isohaline flux $\langle-\partial Q / \partial s\rangle$ is weaker than the neaps, but $\left\langle-\partial^{2} V / \partial s \partial t\right\rangle$ is of the opposite sign. In this case the intensified mixing of spring tides results in stronger diahaline flux than can be supplied by the exchange flow, causing in turn a temporal decrease in the volume of high and low salinity and increase of intermediate salinity, corresponding to a reduction of stratification. These examples show that the exchange flow is not well defined on time scales over which there are significant variations in the distribution of salinity within the estuary because the diahaline flux and the isohaline flux may be out of phase with each other. 


\section{c. Longitudinal variations of TEF, entrainment, and diffusive salt flux in the Hudson estuary}

The above analysis deals with the region between two cross sections with significant separation. The same approach can be used at arbitrarily small separation between sections (ultimately limited by the grid resolution of the numerical model) to address the variation of entrainment and diffusive salt flux along the estuary.

To represent the along-channel variations of entrainment and diffusive salt flux, we divide Eqs. (2.6) and (2.12) by the distance $\Delta x$ between the two adjacent sections $x_{i}$ and $x_{i+1}$ :

$\frac{Q_{e}\left(x_{i}, s\right)}{\Delta x}=\frac{1}{\Delta x} \int_{s}^{s_{0}}-\frac{\partial}{\partial s}\left[Q\left(x_{i}, s\right)-Q\left(x_{i+1}, s\right)-\frac{\partial V\left(x_{i}, s\right)}{\partial t}\right] d s$,

where $Q_{e}\left(x_{i}, s\right) / \Delta x$ indicates the volumetric entrainment per unit along-channel distance at a specific isohaline. It is equal to the lateral integral of the entrainment velocity at a specific isohaline:

$$
\int_{l(x, s)} w_{e} d l=-\frac{\partial Q(x, s)}{\partial x}-\frac{\partial A(x, s)}{\partial t},
$$

where $l(x, s)$ indicates the instantaneous lateral length of isohaline $s$ at section $x$, and $A(x, s)$ indicates the instantaneous area with salinity greater than $s$ at crosssection $x$. Similarly the diffusive salt flux per unit along-channel distance ( $\mathrm{psu} \mathrm{m}^{2} \mathrm{~s}^{-1}$ ) is obtained by

$$
\frac{F_{m}\left(x_{i}, s\right)}{\Delta x}=\frac{1}{\Delta x} \int_{s}^{s_{0}} Q_{e}\left(x_{i}, s\right) d s .
$$

It is equal to the lateral integral of the diffusive salt flux at a specific isohaline $s$.

Using Eqs. (3.1) and (3.3), the along-estuary distribution of entrainment and diffusive salt flux in the Hudson estuary were calculated. Because the TEF quantities represent lateral integrals resolved in salinity space, they are most effectively presented in coordinates of along-channel position and salinity. First, we present the spring-neap average conditions (Fig. 5), for which there is negligible time dependence of the salinity distribution, so the isohaline and diahaline fluxes all balance.

The results plotted versus salinity (Figs. 5b-d) are analogous to the conventional, Eulerian view of the estuarine circulation, except that the vertical coordinate has been replaced with the salinity coordinate. In salinity coordinates, exchange flow drives high-salinity water landward and intermediate-salinity water oceanward (Fig. 5b),
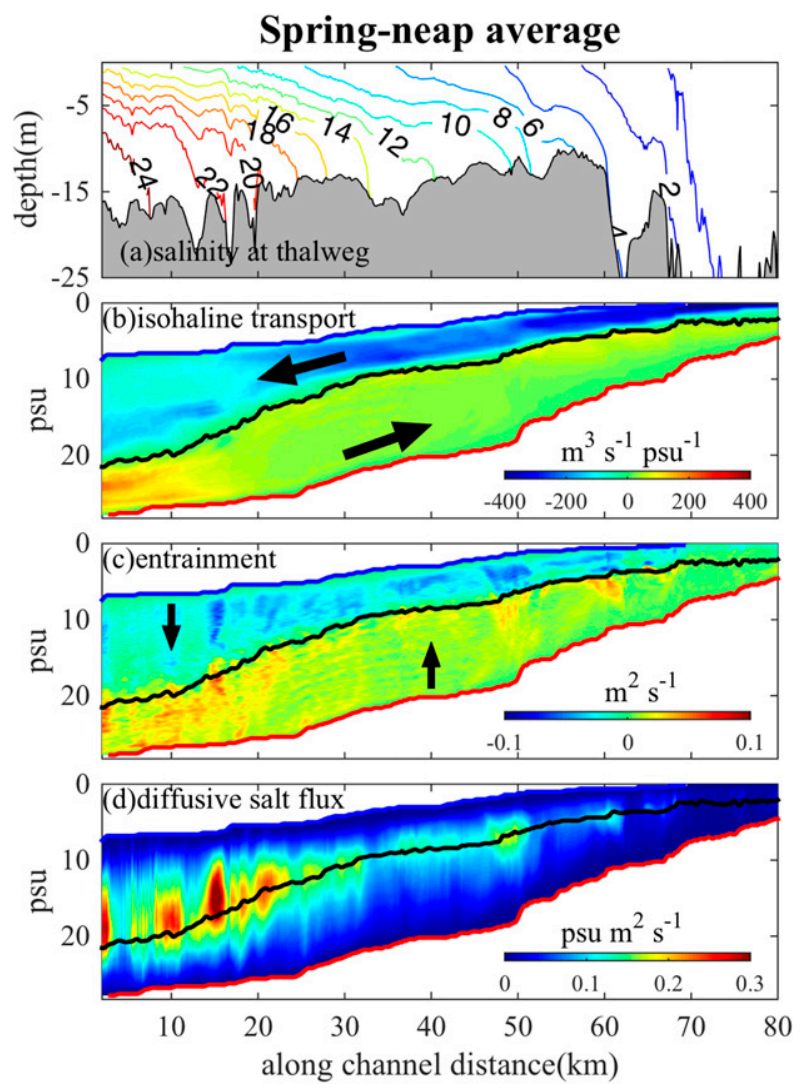

FIG. 5. (a) Spring-neap-averaged salinity along the thalweg in Eulerian coordinates. (b) Longitudinal variations of spring-neapaveraged isohaline transport $\langle-\partial Q / \partial s\rangle$. The blue and red lines indicate the minimum and maximum salinities during the neapspring cycle, respectively. The results in salinity coordinates accounts for all the salinities in one spring-neap cycle, so the results in (b) cover a greater salinity range than the spring-neap-averaged salinity shown in (a). For example, at $75 \mathrm{~km}$, the spring-neapaveraged salinity in (a) is less than $1 \mathrm{psu}$, but the maximum salinity in (b) is about 8 psu. The black line indicates the reversal salinities. (c) Transversely isohaline integrated entrainment $\left(\mathrm{m}^{2} \mathrm{~s}^{-1}\right)$. (d) Transversely isohaline integrated diffusive salt flux $\left(\mathrm{psu} \mathrm{m}^{2} \mathrm{~s}^{-1}\right)$.

with entrainment and mixing occurring between the inflow and outflow water (Figs. 5c,d).

In Fig. 5b, the red line indicates the maximum salinity during spring-neap cycle, which roughly represents the longitudinal variation of bottom salinity. At about $50 \mathrm{~km}$, the maximum salinity decreases more sharply than other regions, which corresponds to the location of a bottom salt front as shown in Fig. 5a. The blue line indicates the minimum salinity during the spring-neap cycle, so the difference between the blue and red lines roughly indicates the strength of the stratification, which decreases along the channel. Note this differs from the Eulerian-averaged stratification due to the temporal variability of surface and bottom salinity. The black line separates saltier inflow from fresher outflow. We call 

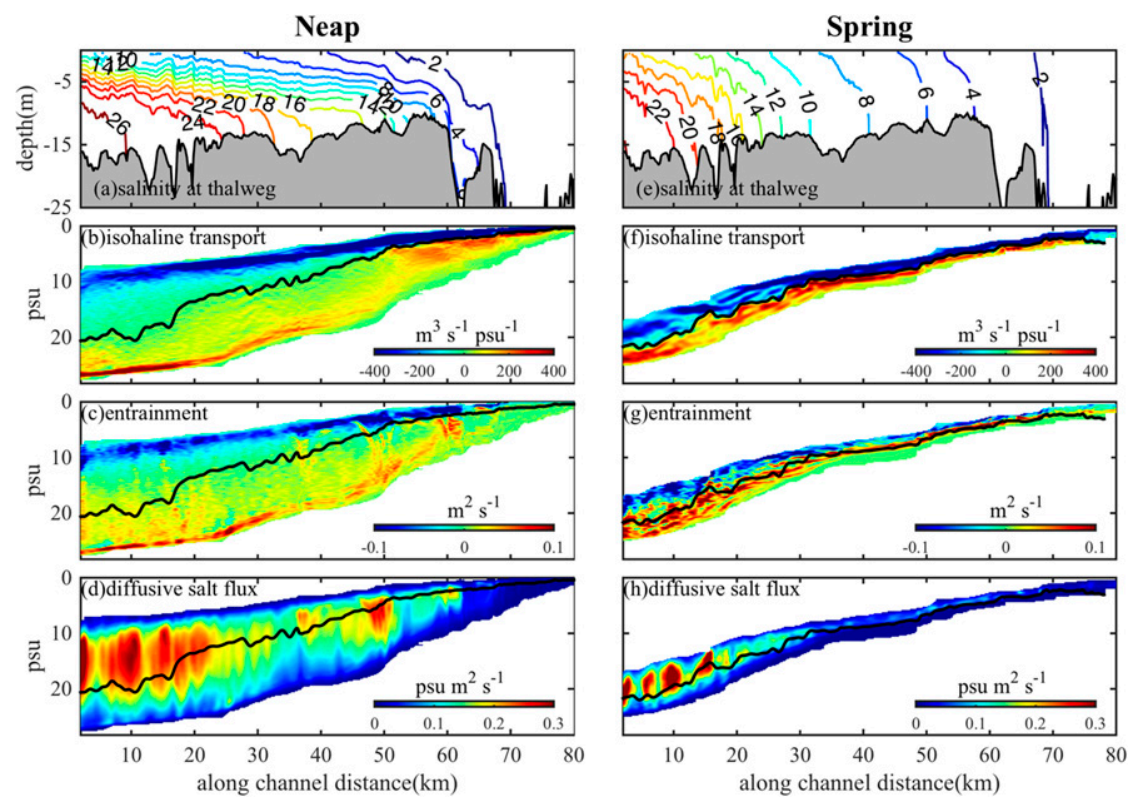

FIG. 6. As in Fig. 5, but for the tidally averaged results during minimum neap and maximum spring tides.

this the reversal surface, which lines up with the reversal salinity (the salinity between inflow and outflow salinities) along the channel. In a steady-state regime, the reversal surface would represent a physical surface, but in highly time-dependent salinity regimes, the vertical position of the reversal surface varies through the spring-neap cycle.

The distribution of entrainment (Fig. 5b) indicates that under steady-state conditions, it is generally upward below the reversal salinity and downward above the reversal salinity. The entrainment is not at all spatially uniform; it shows local maxima that are associated with variations in the mixing distribution and intensity. The distribution of diffusive salt flux (Fig. 5c) shows considerable variability, with a number of zones of intensification. Maximum diffusive salt flux at any alongestuary position is close to the middle of the salinity distribution, usually slightly above the reversal salinity. This is consistent with the example shown in Fig. 3, in which the maximum diffusive salt flux occurs at the salinity that is being exported from that portion of the estuary.

Similar calculations are also done for minimum neap and maximum spring tides with tidal averaging for Eqs. (3.1) and (3.3). During minimum neap tide, isohaline transports as well as entrainment mainly occur in the high- and low-salinity classes (Figs. 6b,c) due to the strong stratification (Fig. 6a). During maximum spring tide, the range of salinity classes at the cross section is much smaller than neap tides, and isohaline transports as well as entrainment mainly occur in the middle salinity classes (Fig. 6f and Fig. 6g) due to the weak stratification (Fig. 6e). During both minimum neap and maximum spring tides, entrainment and diffusive salt flux also show apparently local features (Figs. 6c,d,g,h). The distributions of isohaline and diahaline transports differ during neap and spring tides, and they may affect the time variation of salinity structure. In the following section, the spring-neap variation of isohaline and diahaline salt transports is analyzed to study their influence on the salt content and stratification.

\section{d. Spring-neap variations of TEF, stratification, and cross-reversal surface transport}

Whereas the salinity versus distance representation (shown in Fig. 5 and Fig. 6) provides a comprehensive view of the TEF variables, a simplified representation of the exchange flow is obtained by integrating the transport on either side of the reversal salinity, yielding the volume inflow and volume outflow $Q_{\text {in }}$ and $Q_{\text {out }}$, as shown in Eq. (2.3). The inflow and outflow salt flux due to TEF is given by

$F_{\text {in }}=\left.\int s\left\langle-\frac{\partial Q}{\partial s}\right\rangle\right|_{\text {in }} d s, \quad F_{\text {out }}=\left.\int s\left\langle-\frac{\partial Q}{\partial s}\right\rangle\right|_{\text {out }} d s$

The flux-weighted salinities of inflow and outflow are

$$
s_{\text {in }}=\frac{F_{\text {in }}}{Q_{\text {in }}}, \quad s_{\text {out }}=\frac{F_{\text {out }}}{Q_{\text {out }}} .
$$



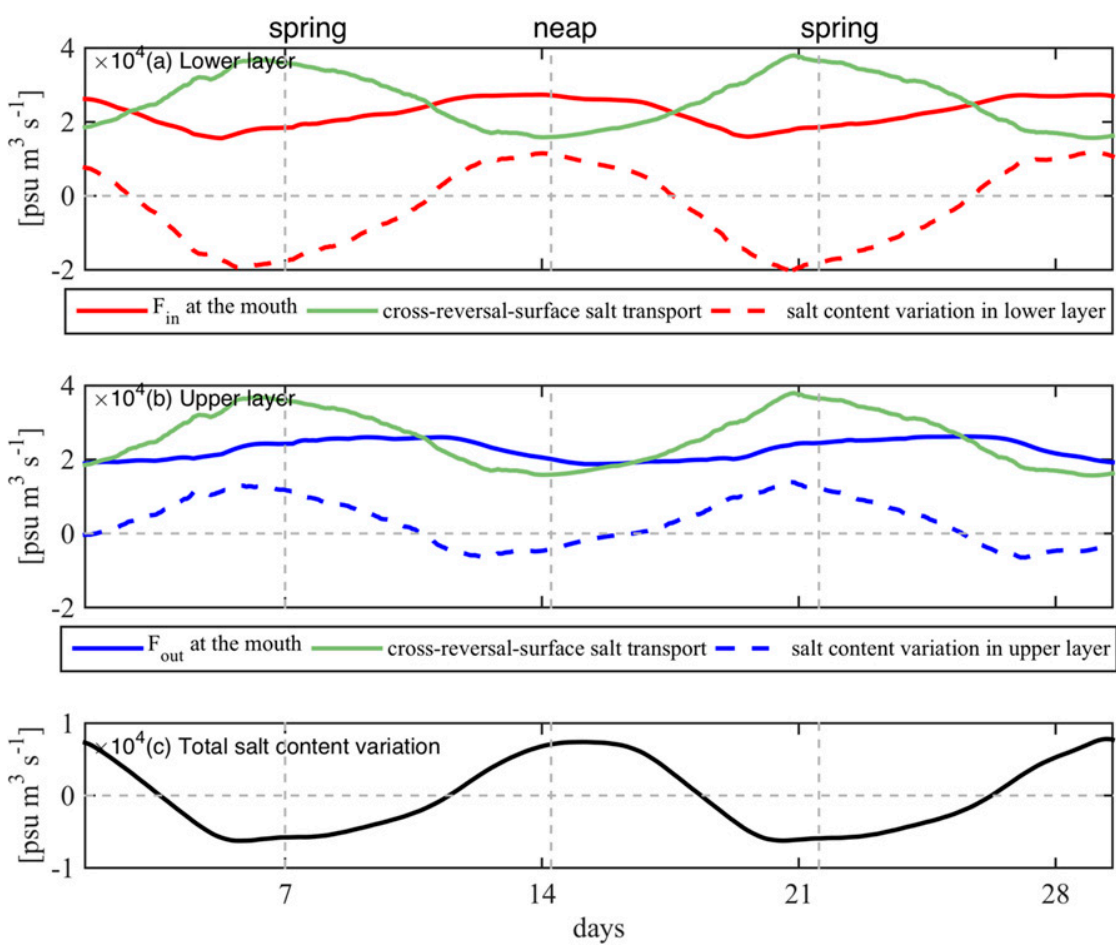

FIG. 7. (a) Spring-neap variations of inflow salt flux $F_{\text {in }}$ (solid red) at the battery, total crossreversal surface salt transport $F_{\text {ei }}$ (green) in the estuary, and salt content variation in the lower layer (dashed red). Positive values indicate salt content increases and negative values indicate salt content decreases. (b) Spring-neap variations of outflow salt flux $F_{\text {in }}$ (solid blue) at the battery, total cross-reversal surface salt transport $F_{\text {ei }}$ (green) in the estuary, and salt content variation in the upper layer (dashed blue). (c) Total salt content variation in the whole estuary.

Using the two-layer structure defined by the reversal surface, the diahaline salt flux can be quantified by the sum of the entrainment salt flux and diffusive salt flux across the reversal surface. The cross-reversal surface salt flux integrated over the full length of the estuary is

$$
F_{\mathrm{ei}}=\left\langle\int_{X_{L}} \frac{1}{\Delta x}\left[Q_{e}\left(x_{i}, s_{i}\right) s_{i}+F_{m}\left(x_{i}, s_{i}\right)\right] d x\right\rangle,
$$

where $F_{\text {ei }}$ indicates the tidally averaged cross-reversal surface salt flux, that is, the sum of the entrainment salt flux and diffusive salt flux across the reversal surface; $X_{L}$ indicates the length of salt intrusion; and $s_{i}$ indicates the reversal salinity. Under steady-state conditions, the isohaline salt flux at the mouth is equal to the diahaline salt flux $F_{\mathrm{e} i}$ :

$$
F_{\text {ei }}=F_{\text {in }}=F_{\text {out }} \cdot
$$

However, the estuarine salt balance is typically far from steady state, so the above relationship is only valid over long averaging periods. For the time-dependent situation,

$$
F_{\text {ei }}=F_{\text {in }}-\underbrace{\frac{d}{d t}\left\langle\int_{V_{\text {lo }}} s d V\right\rangle}_{\text {Storage of lower layer }}=F_{\text {out }}+\underbrace{\frac{d}{d t}\left\langle\int_{V_{\text {up }}} s d V\right\rangle}_{\text {Storage of upper layer }},
$$

where $V_{\text {lo }}$ indicates the volume of the lower layer under reversal surface, $V_{\text {up }}$ indicates the volume of the upper layer above the reversal surface, and $d / d t\left\langle\int_{V_{10}} s d V\right\rangle$ and $d / d t\left\langle\int_{V_{\text {up }}} s d V\right\rangle$ indicate the time rate of change of tidally averaged salt content in the lower and upper layers, respectively. Equation (3.8) indicates that the phase shift between diahaline salt flux and isohaline salt flux would affect the salt content in the lower and upper layers and then affect the total salt content and stratification. All terms in Eq. (3.8) are obtained with the Hudson model results to show how the phase shift between diahaline and isohaline salt transports affects the spring-neap variations of salt content and stratification (Fig. 7). The temporal variation of total salt content in the whole estuary is obtained with the summation of $d / d t\left\langle\int_{V_{\mathrm{lo}}} s d V\right\rangle$ and $d / d t\left\langle\int_{V_{\mathrm{up}}} s d V\right\rangle$. 


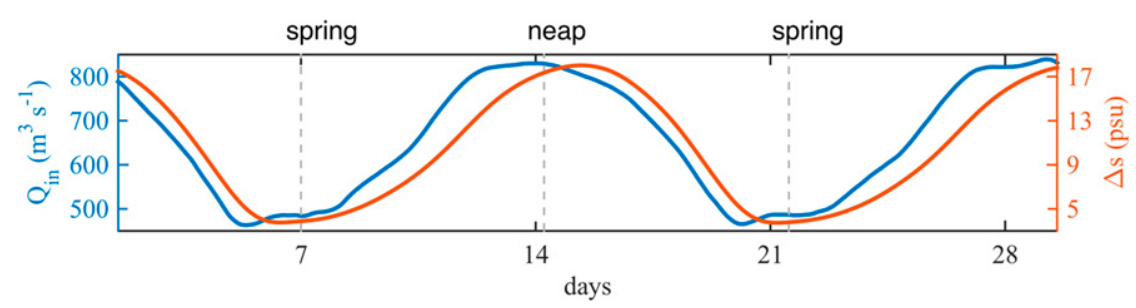

FIG. 8. Along-channel-averaged (from mouth to $20 \mathrm{~km}$ ) volume inflow from TEF (blue) and stratification (orange). Stratification $\Delta s$ indicates the difference between tidally averaged bottom and surface salinity.

The spring-neap variability of $F_{\text {in }}, F_{\text {ei }}$, and $F_{\text {out }}$ results in a pronounced contribution of the time variability of the salt content in the two layers and the whole estuary. In the lower layer (Fig. 7a), $F_{\text {in }}$ reaches its maximum close to neap tides. The large time variation of salt content occurs because $F_{\text {in }}$ and $F_{\text {ei }}$ are almost completely out of phase with each other. The maximal exchange flow transports salt into the lower layer during neap tides, but the diahaline salt flux (cross-reversal surface salt flux) reaches its maximum close to spring tides. This phase shift results in the increase of salt content during neap tides due to the excess isohaline transport and the decrease during spring tides due to excess diahaline transport. In the upper layer (Fig. 7b), $F_{\text {ei }}$ is larger than $F_{\text {out }}$ during spring tides and smaller than $F_{\text {out }}$ during neap tides, resulting in the increase of salt content during spring tides and decrease during neap tides. Therefore, because of the phase shift between isohaline and diahaline salt transports, there is an about 7-day phase shift between the temporal variations of the salt content in the lower layer and upper layer. The variation of salt content in the lower layer is larger than that in the upper layer, resulting in the increase of salt content in the whole estuary during neap tides and decrease during spring tides (Fig. $7 \mathrm{c}$ ). Note that the nearly 7-day phase shift between the salt content in the lower and upper layers is roughly consistent with the spring-neap variation of stratification.

The relationships between exchange flow and stratification are illustrated more clearly in the spring-neap variations of along-channel-averaged $Q_{\text {in }}$ and stratification in the lower Hudson estuary (from mouth to $20 \mathrm{~km}$; Fig. 8). The spring-neap variation of $Q_{\text {in }}$ is consistent with $F_{\text {in }}$, with its maximum close to neap tides. This is consistent with Eulerian observations of the estuarine circulation in the Hudson estuary (e.g., Geyer et al. 2000), which showed it is modulated by the springneap variation in tidally generated bottom drag. As discussed above, because of the phase shift between isohaline and diahaline transports, stratification also shows a strong spring-neap variation, consistent with many estuarine observations (Haas 1977; Geyer and Cannon 1982). Another interesting point is that there is about 2-day phase shift between the greatest exchange flow and the strongest stratification. These results clearly illustrate the coupling between stratification, circulation, and spring-neap variations in mixing [see MacCready and Geyer (2010) for a review]. Briefly, stratification may be regarded as the result of the competition between tidal stirring and mean straining by the exchange flow. Exchange flow drives high-salinity water landward near the bottom and low-salinity water seaward near the surface, which increases stratification. Tidal stirring transports salt up from the bottom to the surface, which decreases the stratification. When exchange flow is the greatest during the minimum neap tide, tidal stirring is weak, so the influence of exchange flow exceeds tidal stirring, which continues to increase stratification, so there is an about 2-day phase shift between the greatest exchange flow and the strongest stratification. As tidal amplitude increases, the influence of tidal stirring exceeds the exchange flow, so the stratification decreases.

To summarize the spring-neap variations, during neap tides, the exchange flow is larger, but cross-reversal surface transport is smaller, resulting in the increase of stratification, and $F_{\text {in }}$ is larger than $F_{\text {out }}$, resulting in the increase of salt content in the estuary. During spring tides, the exchange flow is smaller, but cross-reversal surface transport is larger, resulting in the decrease of stratification, and $F_{\text {in }}$ is smaller than $F_{\text {out }}$, resulting in the decrease of salt content in the estuary. The almost 7-day lag between the maximum isohaline flux and diahaline flux results in the dramatic changes in salinity structure that occur in partially mixed estuaries like the Hudson.

\section{Discussion}

\section{a. Mechanism for the local features of diffusive salt flux}

As shown in Figs. 5d and 9, diffusive salt flux is mainly intensified at intermediate salinities in the lower 


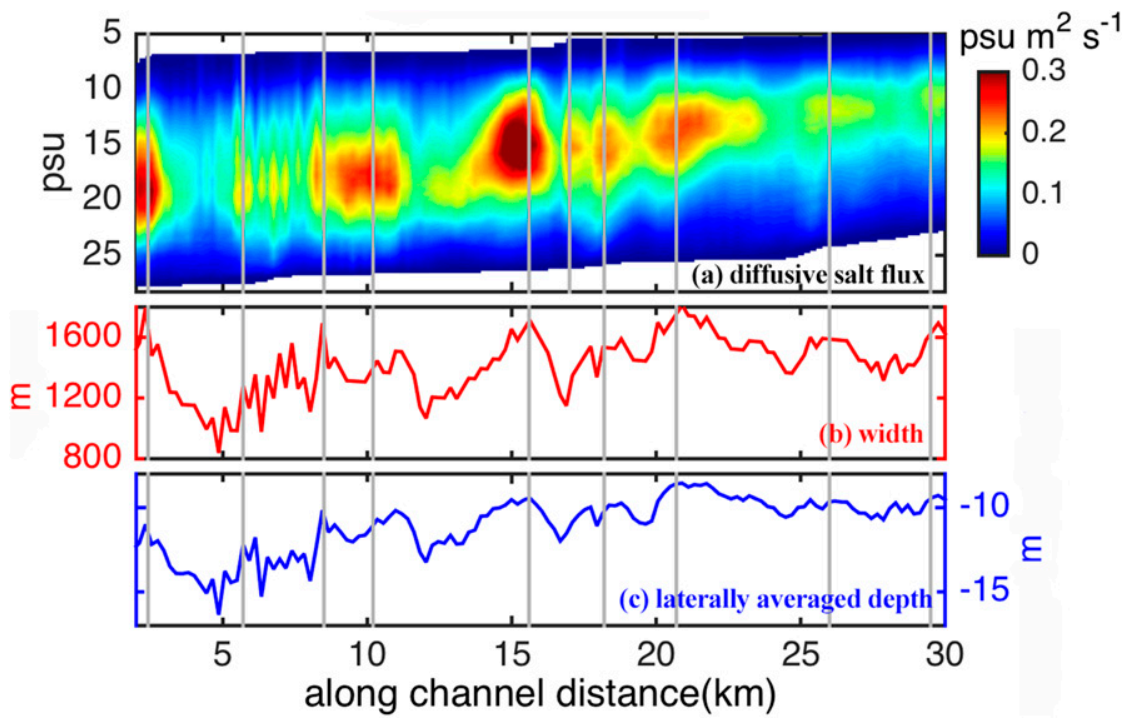

FIG. 9. (a) Spring-neap-averaged and transversely integrated diahaline diffusive salt flux in the lower Hudson estuary. (b),(c) Along-channel variations of width and depth of the lower Hudson estuary.

estuary (below $30 \mathrm{~km}$ ), with particular intensification at some specific locations, such as 10,15 , and $18 \mathrm{~km}$. As shown in Fig. 9, the intensified mixing occurs in the wider and shallower regions of the estuary. Because of the natural adjustment, in the lower Hudson estuary, the wider regions are corresponding to the shallower regions (Fig. 9). Following Chant and Wilson (2000), the intensification at the wider and shallower locations may be explained with the shear tendency equation for a laterally uniform flow with changing width:

$\left(\frac{\partial}{\partial t}+u \frac{\partial}{\partial x}\right) \frac{\partial u}{\partial z}=\frac{\partial u}{B \partial z}\left(u \frac{\partial B}{\partial x}+w \frac{\partial B}{\partial z}\right)+\frac{g}{\rho} \frac{\partial \rho}{\partial x}-\frac{\partial^{2}}{\partial z^{2}} \overline{u^{\prime} w^{\prime}}$,

where $B$ is the width. This equation indicates that downstream (during flood, downstream means landward; during ebb, downstream means oceanward) increasing width causes an increase in shear, which in turn leads to intensified shear-induced mixing.

\section{b. Dissipation of salinity variance and numerical mixing}

Burchard and Rennau (2008) use the balance of salinity variance to determine the amount of mixing accomplished by the turbulence closure and to distinguish it from numerically generated mixing. The turbulence closure extracts variance at a rate equal to the molecular dissipation of salinity variance:

$$
\chi_{s}=2 \overline{s^{\prime} w^{\prime}} \frac{\partial s}{\partial z}
$$

where the rhs of Eq. (4.2) is the dissipation of Reynoldsaveraged salinity variance or the production of turbulent salinity variance, which is equal on appropriate temporal and spatial averaging scales to the molecular dissipation of salinity variance (Osborn and Cox 1972). The volume integral of salinity variance dissipation between two cross sections can be written as

$\iiint_{V} 2 \overline{s^{\prime} w^{\prime}} \frac{\partial s}{\partial z} d x d y d z=2 \int_{0}^{s_{0}}\left[\int_{A_{s}(s)} \overline{s^{\prime} w^{\prime}} d x d y\right] d s$,

where $V$ indicates the volume between the two cross sections, and $A_{s}(s)$ indicates the area of an isohaline surface with salinity $s$ between the two cross sections. When diffusive salt flux is all induced by turbulence, the term in the bracket of the rhs of Eq. (4.3) is equal to $F_{m}$ in section 2 , so

$$
2 \int_{0}^{s_{0}} F_{m} d s=\iiint_{V} 2 \overline{s^{\prime} w^{\prime}} \frac{\partial s}{\partial z} d x d y d z
$$

Therefore, with Eqs. (2.6), (2.12), and (4.4), the volume integral of salinity variance dissipation can be quantified using the divergence of isohaline transports at the boundaries and the salinity variation in the volume.

In numerical models, diffusive salt flux is not only induced by turbulence but also by numerical mixing, so 


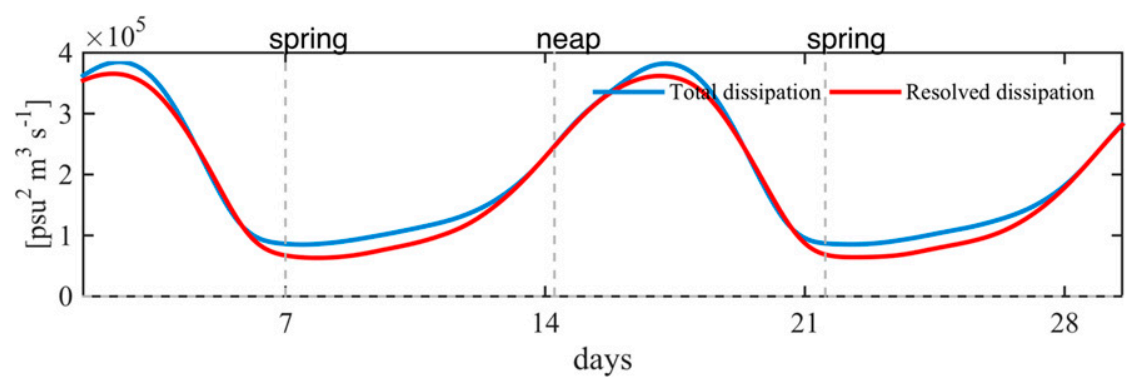

FIG. 10. Tidally averaged and estuarine integral of dissipation rate of salinity variance due to total mixing, which is obtained from the isohaline methods [Eqs. (2.6), (2.12), and (4.4)] (blue). Resolved dissipation in the Hudson model, which is obtained from the estuarine volume integral of $K_{s}(\partial s / \partial z)^{2}$ (red). The difference between the blue and red lines is due to numerical mixing.

$$
\begin{aligned}
2 \int_{0}^{s_{0}} F_{m} d s & =\iiint_{V} 2 \overline{s^{\prime} w^{\prime}} \frac{\partial s}{\partial z} d x d y d z+\text { numerical mixing } \\
& =\iiint_{V} 2 K_{s}\left(\frac{\partial s}{\partial z}\right)^{2} d x d y d z+\text { numerical mixing }
\end{aligned}
$$

where $K s$ indicates the turbulent diffusivity coefficient from the model output. When $V$ is chosen as the volume of the entire estuary, we can obtain the volume integral of salinity variance dissipation due to the total mixing as well as turbulent mixing (resolved mixing) and numerical mixing over the entire estuary.

The dissipation of salinity variance based on the left term of Eq. (4.5) is shown in Fig. 10, along with the dissipation based on the turbulence closure (the first term on the rhs), integrated over the entire estuarine volume. These two approaches nearly agree, which confirms that the integral method closely approximates the resolved mixing, providing confirmation of the methodology. The resolved mixing is slightly less than the integral estimate; this difference is explained by the contribution of numerical mixing, as discussed in the next paragraph. Interestingly, the dissipation of salinity variance is actually minimal during spring tides, when the most energetic turbulence occurs. The maximum mixing of salt is found to occur during the transition from neaps to springs. This matches the time when stratification decreases most rapidly (Fig. 8), which is consistent with the rapid decrease in salinity variance. The phase shift of the mixing with respect to the springneap cycle indicates that maximum mixing occurs when there is both intensified turbulence and significant vertical salinity gradient.

Equation (2.12) for the salt flux due to mixing and Eq. (4.5) for the salinity variance dissipation are based on the total exchange of salt between salinity classes within the model. This includes both the explicit specification of diahaline mixing associated with the turbulence closure as well as numerical mixing associated with truncation errors in the advection scheme (Shchepetkin and McWilliams 1998; Burchard et al. 2002). The difference between the blue and red lines in Fig. 10 indicates the numerical mixing of the Hudson model, which is small in this particular case. This method of calculating numerical mixing does not provide as much detail about the temporal and spatial variations of numerical mixing as the approach of Burchard and Rennau (2008), but it has the advantage that the calculation can be performed with only first-order model variables (including the eddy diffusivity), without requiring the in-line calculation of salinity variance during the model run as required by Burchard and Rennau (2008). Therefore, it provides a simple alternative means of estimating modelgenerated mixing.

\section{Conclusions}

This paper extends the total exchange flow methodology to study the relationship among the total exchange flow, entrainment, diffusive salt flux, and dissipation rate of salinity variance and their temporal and spatial variations in estuaries. Entrainment, diffusive salt flux, and dissipation of salinity variance are all calculated as simple integrals of the exchange flow in salinity coordinates. Through adding diahaline fluxes into the total exchange flow methodology, this paper completes the circuit of estuarine circulation based on salinity coordinates. Through including the temporal variations of the volumes in different salinity classes, the method is developed to study the temporal and spatial variations of TEF, entrainment, and diffusive salt flux. With the developed method, the longitudinal and spring-neap variations of exchange flow and mixing and their influence on the stratification and salt content are analyzed 
with a validated numerical model of the Hudson estuary. Over a long enough time average, the isohaline (TEF) and diahaline (cross reversal surface) transports are equal. However, in a spring-neap cycle, there is about a 7-day phase lag between isohaline and diahaline transport, which leads to the spring-neap variations of stratification and salt content in the estuary. Diahaline transport and mixing also vary along the channel, which are intensified in certain regions where the shears are amplified by changes in estuarine width.

The method also can be used to quantify the volume integral of dissipation of the salinity variance. Whereas this is an important quantity in its own right for assessing the processes responsible for spring-neap variation in stratification, it is also useful for distinguishing resolved mixing (as estimated by turbulence closure) with numerically generated mixing. The method described here has the advantage over that of Burchard and Rennau (2008) that it does not require any in-line calculations of second-order quantities to estimate numerical mixing.

As discussed in the introduction, one advantage of the total exchange flow methodology is that it satisfies the Knudsen relations, thus allowing the rigorous examination of the tidally averaged salt balance associated with along-estuary transport. This paper shows that total exchange flow methodology also allows the diahaline salt transport to be quantified and thereby to quantify and distinguish entrainment and diffusive salt flux. In a further step, the dissipation rate of salinity variance can be quantified. This paper demonstrates that total exchange flow is effective for diagnosing the diahaline salt transport in the Hudson estuary, but would it be applicable to other estuarine regimes? Total exchange flow has been applied to investigate the along-estuary transport in a variety of estuarine regimes, including the fjord regime of Puget Sound (Sutherland et al. 2011) and the salt wedge regime of the Merrimack River (Chen et al. 2012). The same approach as presented here could be extended to quantify the diahaline processes in these environments as well. The main constraint that determines whether TEF may be effective is that the salinity has enough variation and spatial structure in the estuary to provide an alternative coordinate system for defining the transport. An embayment with little freshwater inflow would not lend itself to the application of TEF. In any case, there is no requirement that the estuarine circulation be the dominant mechanism of exchange for this analysis to be effective, as illustrated by the effective use of TEF in the tidally dominated Merrimack River (Chen et al. 2012).

Acknowledgments. T. Wang was supported by the Open Research Fund of State Key Laboratory of
Estuarine and Coastal Research (Grant SKLECKF201509), the Fundamental Research Funds for the Central Universities (Grant 2017B03514), and the Strategic Priority Research Program of the Chinese Academy of Sciences (Grant XDA11010203). W. R. Geyer was supported by NSF Grant OCE 0926427 and ONR Grant N00014-16-1-2948. P. MacCready was supported by NSF Grant OCE-1634148. T. Wang would like to acknowledge Hui Wu for his advice to this paper.

\section{REFERENCES}

Bowen, M. M., and W. R. Geyer, 2003: Salt transport and the timedependent salt balance of a partially stratified estuary. J. Geophys. Res., 108, 3158, doi:10.1029/2001JC001231.

Burchard, H., and H. Rennau, 2008: Comparative quantification of physically and numerically induced mixing in ocean models. Ocean Modell., 20, 293-311, doi:10.1016/ j.ocemod.2007.10.003.

_ K K. Bolding, T. P. Rippeth, A. Stips, J. H. Simpson, and J. Sündermann, 2002: Microstructure of turbulence in the northern North Sea: A comparative study of observations and model simulations. J. Sea Res., 47, 223-238, doi:10.1016/ S1385-1101(02)00126-0.

Chant, R. J., and R. E. Wilson, 2000: Internal hydraulics and mixing in a highly stratified estuary. J. Geophys. Res., 105, 1421514 222, doi:10.1029/2000JC900049.

Chen, S.-N., W. R. Geyer, D. K. Ralston, and J. A. Lerczak, 2012: Estuarine exchange flow quantified with isohaline coordinates: Contrasting long and short estuaries. J. Phys. Oceanogr., 42, 748-763, doi:10.1175/JPO-D-11-086.1.

Doos, K., and D. Webb, 1994: The Deacon cell and the other meridional cells of the Southern Ocean. J. Phys. Oceanogr., 24, 429-442, doi:10.1175/1520-0485(1994)024<0429: TDCATO $>2.0 . C O ; 2$.

Dronkers, J., and J. van de Kreeke, 1986: Experimental determination of salt intrusion mechanisms in the Volkerak estuary. Neth. J. Sea Res., 20, 1-19, doi:10.1016/0077-7579(86)90056-6.

Fischer, H. B., 1976: Mixing and dispersion in estuaries. Annu. Rev. Fluid Mech., 8, 107-133, doi:10.1146/annurev.fl.08.010176.000543.

Geyer, W. R., and G. A. Cannon, 1982: Sill processes related to deep water renewal in a fjord. J. Geophys. Res., 87, 7985, doi:10.1029/JC087iC10p07985.

_ stratified estuary. Buoyancy Effects on Coastal and Estuarine Dynamics, D. G. Aubrey and C. T. Friedrichs, Eds., Coastal Estuarine Studies, Vol. 53, Amer. Geophys. Union, 213-226.

_ , and P. MacCready, 2014: The estuarine circulation. Annu. Rev. Fluid Mech., 46, 175-197, doi:10.1146/annurev-fluid-010313-141302.

- J. H. Trowbridge, and M. M. Bowen, 2000: The dynamics of a partially mixed estuary. J. Phys. Oceanogr., 30, 2035-2048, doi:10.1175/1520-0485(2000)030<2035:TDOAPM >2.0.CO;2.

Haas, L. W., 1977: The effect of the spring-neap tidal cycle on the vertical salinity structure of the James, York and Rappahannock Rivers, Virginia, U.S.A. Estuarine Coastal Mar. Sci., 5, 485-496, doi:10.1016/0302-3524(77)90096-2.

Hansen, D. V., and M. Rattray, 1965: Gravitational circulation in straits and estuaries. J. Mar. Res., 23, 104-122.

Hunkins, K., 1981: Salt dispersion in the Hudson estuary. J. Phys. Oceanogr., 11, 729-738, doi:10.1175/1520-0485(1981)011<0729: SDITHE $>2.0 . \mathrm{CO} ; 2$. 
Jay, D., and J. D. Smith, 1990: Circulation, density distribution and neap-spring transitions in the Columbia River estuary. Prog. Oceanogr., 25, 81-112, doi:10.1016/0079-6611(90)90004-L.

Knudsen, M., 1900: Ein hydrographischer Lehrsatz. Ann. Hydrogr. Marit. Meteor., 28, 316-320.

Lerczak, J. A., W. R. Geyer, and R. J. Chant, 2006: Mechanisms driving the time-dependent salt flux in a partially stratified estuary. J. Phys. Oceanogr., 36, 2296-2311, doi:10.1175/ JPO2959.1.

_ — - and D. K. Ralston, 2009: The temporal response of the length of a partially stratified estuary to changes in river flow and tidal amplitude. J. Phys. Oceanogr., 39, 915-933, doi:10.1175/2008JPO3933.1.

Lewis, R. E., and J. O. Lewis, 1983: The principle factors contributing to the flux of salt in an arrow, partially stratified estuary. Estuarine Coastal Mar. Sci., 16, 599-626, doi:10.1016/ 0272-7714(83)90074-4.

Lumpkin, R., and K. Speer, 2007: Global ocean meridional overturning. J. Phys. Oceanogr., 37, 2550-2562, doi:10.1175/ JPO3130.1.

MacCready, P., 2011: Calculating estuarine exchange flow using isohaline coordinates. J. Phys. Oceanogr., 41, 1116-1124, doi:10.1175/2011JPO4517.1.

_ , and W. R. Geyer, 2001: Estuarine salt flux through an isohaline surface. J. Geophys. Res., 106, 11629-11 637, doi:10.1029/ 2001JC900006.

- , and - 2010: Advances in estuarine physics. Annu. Rev. Mar. Sci., 2, 35-58, doi:10.1146/annurev-marine-120308-081015.

— R. D. Hetland, and W. R. Geyer, 2002: Long-term isohaline salt balance in an estuary. Cont. Shelf Res., 22, 1591-1601, doi:10.1016/S0278-4343(02)00023-7.

MacDonald, D. G., and W. R. Geyer, 2004: Turbulent energy production and entrainment at a highly stratified estuarine front. J. Geophys. Res., 109, C05004, doi:10.1029/2003JC002094.

_ ability of vertical salt flux in a highly stratified estuary. J. Geophys. Res., 113, C09022, doi:10.1029/2007JC004620.

Mazloff, M. R., R. Ferrari, and T. Schneider, 2013: The force balance of the Southern Ocean meridional overturning circulation. J. Phys. Oceanogr., 43, 1193-1208, doi:10.1175/JPO-D-12-069.1.

McDougall, T. J., and Y. You, 1990: Implications of the nonlinear equation of state for upwelling in the ocean interior. J. Geophys. Res., 95, 13263-13276, doi:10.1029/ JC095iC08p13263.

—, and W. K. Dewar, 1998: Vertical mixing and cabbeling in layered models. J. Phys. Oceanogr., 28, 1458-1480, doi:10.1175/1520-0485(1998)028<1458:VMACIL > 2.0.CO;2.

McIntosh, P. C., and T. J. McDougall, 1996: Isopycnal averaging and the residual mean circulation. J. Phys. Oceanogr., 26, 1655-1660, doi:10.1175/1520-0485(1996)026<1655:IAATRM > 2.0.CO;2.

Okubo, A., 1973: Effect of shoreline irregularities on streamwise dispersion in estuaries and other embayments. Neth. J. Sea Res., 6, 213-224, doi:10.1016/0077-7579(73)90014-8.

Osborn, T. R., and C. S. Cox, 1972: Oceanic fine structure. Geophys. Fluid Dyn., 3, 321-345, doi:10.1080/03091927208236085.

Pritchard, D. W., 1956: The dynamic structure of a coastal plain estuary. J. Mar. Res., 15, 33-42.

Ralston, D. K., W. R. Geyer, and J. A. Lerczak, 2008: Subtidal salinity and velocity in the Hudson River estuary: Observations and modeling. J. Phys. Oceanogr., 38, 753-770, doi:10.1175/2007JPO3808.1.

Shchepetkin, A. F., and J. C. McWilliams, 1998: Quasi-monotone advection schemes based on explicit locally adaptive dissipation. Mon. Wea. Rev., 126, 1541-1580, doi:10.1175/ 1520-0493(1998)126<1541:QMASBO > 2.0.CO;2.

Sutherland, D. A., P. MacCready, N. S. Banas, and L. F. Smedstad, 2011: A model study of the Salish Sea estuarine circulation. J. Phys. Oceanogr., 41, 1125-1143, doi:10.1175/ 2011JPO4540.1.

Townsend, R. D., and D. R. Johnson, 1985: A diagnostic study of the isentropic zonally averaged mass circulation during the First GARP Global Experiment. J. Atmos. Sci., 42, 1565-1579, doi:10.1175/1520-0469(1985)042<1565:ADSOTI>2.0.CO;2.

Wang, T., W. R. Geyer, P. Engel, W. Jiang, and S. Feng, 2015: Mechanisms of tidal oscillatory salt transport in a partially stratified estuary. J. Phys. Oceanogr., 45, 2773-2789, doi:10.1175/JPO-D-15-0031.1.

Warner, J. C., W. R. Geyer, and J. Lerczak, 2005: Numerical modeling of an estuary: A comprehensive skill assessment. J. Geophys. Res., 110, C05001, doi:10.1029/2004JC002691.

_ _ _ and H. G. Arango, 2010: Using a composite grid approach in a complex coastal domain to estimate estuarine residence time. Comput. Geosci., 36, 921-935, doi:10.1016/ j.cageo.2009.11.008. 